\title{
Digital Technologies in Finance: Modernity and Prospects
}

\author{
Anatoliy Suprun ${ }^{1}$, Tetiana Petrishina ${ }^{1 *}$, Marina Sadovenko ${ }^{1}$, Natalya Voloshanyuk ${ }^{1}$ and Serhii Khodakevich $^{2}$ \\ ${ }^{1}$ State University of Economics and Technology, Kryvyi Rih 50000, Ukraine \\ 2 Kyiv National Economic University named after Vadym Hetman, Kyiv 03057, Ukraine
}

\begin{abstract}
Digital technologies have radically changed all financial relations in society. A new financial business ecosystem based on the use of digital technologies is rapidly forming. The article examines the recent changes in the financial sector under the influence of new technologies. The benefits received by consumers of financial services and financial institutions from the introduction of digital technologies are assessed. The survey of financial services consumers conducted by the authors of the article to some extent reflects the situation with the use of digital financial services in Ukraine. However, the process of digitalization is still far from complete. The formation of a new ecosystem, along with opportunities, generates new risks. There are new, often complex and not always clear to the general public financial products and services. The low level of financial and digital literacy forms a platform for manipulation, falsification and outright fraud. The problem of cybersecurity is relevant. The situation with employment in the financial sector in the medium and long term is rather uncertain. System errors are a risk factor too which can cause significant damage to both individuals and legal entities. The article provides examples of system errors and identifies their main cause - low qualification of information technology professionals working in the public sector. The vision of the future development of the financial sphere within the framework of digitalization is formed, the necessary changes at the private and public levels are determined.
\end{abstract}

\section{Introduction}

The modern digital technologies provide many opportunities for the development of the financial business, but they contain many threats and dangers too. Digital technologies in finances are real, although they are far from completion. New financial instruments, such as virtual assets, they endanger the existence of a fundamental financial model that is based on credit money issued by the banking system. Many questions about the functioning of neofinance and neobanking arise at the household level. Although digital financial technologies simplify and accelerate many business processes, they require users to be financially and digitally literate. Under the new conditions, public bodies to control financial business, which is now rapidly virtualizing, has become increasingly difficult. It is necessary to improve state supervision and ensure the interests of society in obtaining reliable instruments of payment and storage of valuables. A new financial system will have to form in the next decade, and all actors in this system have to work to make it fair, secure and efficient for society as a whole.

\subsection{Literature Review}

The question of the functioning of the financial system in a digital economy has been raised by many scientists, public institutions and non-governmental organizations.
In-depth studies in the field of digital and information technology have been made by K.Skinner $[8,10]$. The impact of artificial intelligence on the near future of digital business is described in sufficient detail by Kai-fu Lee [5]. The concept of blockchain technologies application in finance was opened by M. Iansiti, K. Lakhani [2], R.Bukht, R.Heeks [15]. The scholar writings of mentioned scientists consider the impact of digitalization on socio-economic processes, including the financial sphere. The most successful examples of fintech implementation in the financial sector in Ukraine are Privatbank with the Privat24 system and Universal Bank with the monobank system. The creation and introduction of the monobank to the market is described in the book-interview with the original author by D. Dubilet [13]. Significant attention is paid to the use of digital technologies in the financial sphere by intergovernmental associations, such as the EU and the UN. Digitalization concepts of the financial sphere are presented in EU Directives and UN reports. In Ukraine, the process of digitalization of the financial and credit system led by the NBU. This is clearly reflected in its regulations, regulatory acts and legislative initiative (in particular, the preparation of legislation on the implementation of PSD2 regulations and the implementation of the open banking concept). The Verkhovna Rada of Ukraine and the Ministry of Digital Development joined the digitalization and virtualization processes by adopting in the first reading on December 2, 2020 the draft Law on Virtual Assets [21], which in

* Corresponding author: petrishina to@kneu.dp.ua 
particular legalizes cryptocurrency. Despite the significant quantity of materials, there is still space for further scientific research, because the finance digitalization process of itself is still far from complete. It should be noted that in existing studies, much more attention is paid to the benefits of digitalization and much less risk.

\section{Problem statements}

In view of the above, there is a task to substantiate the basic principles of functioning of the modern and future financial system in the digital economy realities and identify safe areas for its development. At the same time, attention is paid not only to the benefits but also to the risks of the neofinance functioning for modern society. Social environment in the form of researchers, private financial institutions and the state should form an understanding of the processes of digitalization in finance and a vision of opportunities and threats in the future. The purpose of the article is to form a vision of financial processes future based on an analysis of present changes that digital technology has brought to the financial industry.

\section{Material presentation and results}

First of all, the society of the 21st Century is characterized as informational and digital. Digital technologies are penetrating all spheres of social and economic life. The formation of a digital society has many advantages that cannot be overlooked (speed of information transfer, work with data for the benefit of business and society, a new culture of entertainment), but also has a number of obvious and hidden threats.

The debate about the new world continues at all levels: from domestic and educational to state and global.

In 2019, the UN produced a report on the Internet and technology called «The Age of Digital Interdependence» [1], which set goals until 2030 for UN member states in the use of digital technologies for the benefit of society. The basic principle announced in the document is the availability of all users to the Internet and their ability to use specialized services (public services, finance, medicine etc). One of the tasks for governments is ensuring access to financial services (through mobile money, identification / authorization and e-commerce).

The front office decisions of financial institutions are on the surface. Recent advances in remote customer service, the ability to transfer funds quickly and cheaply not only nationally but also internationally, mobile phone payment form a new ecosystem of financial institutions' relations with the client. These financial services have been developing rapidly over the past decade. Particularly noteworthy is their positive impact on the development of financial services in developing countries (in a number of African countries, mobile banking is practically the only available banking service for the general population) and in the context of the COVID-19 coronavirus pandemic on a global scale.
But most digital financial decisions are hidden from consumers and concern the back offices of financial institutions

The financial institutions back office functioning models have undergone revolutionary changes over the past 3-5 years, which has provided cost optimization in internal business processes at almost every government level.

In a broad sense, the back office of a financial institution provides internal business processes for asset and liability management. In a banking institution, these are such operations as assessing the quality of the loan portfolio and individual borrowers, opening, closing and maintaining customer accounts, execution of trade and depository agreements with securities. In insurance companies, the operations and internal business processes of the back office are similar to banking, but have insurance specifics (for example, actuarial calculations).

The use of technologies related to data collection and processing, together with high-performance computing capabilities, has allowed automating decision-making processes in the field of pricing, capital allocation, investment and insurance portfolio management.

The use of cloud computing provides shared access to communication networks and data warehouses, instant access to libraries, the use of applications, the ability to use computing resources at any point where there is Internet. Management decisions based on cloud technologies optimize the costs of the back office.

Budgeting has received a new impetus, as coordination between the main back office and structural units has reached a new level through the use of a single technology platform, reporting standards and regulations, electronic document management, bringing financial responsibility centers closer to performance targets and indicators.

In 2020, financial institutions began to make more active use of blockchain technology in the management of both the front office and the back office. M. Iansiti and $\mathrm{K}$. Lakhani substantiated in their scientific works that the financial industry will become a pioneer in the introduction of blockchain technologies [2].

Based on blockchain technology, the world's first cryptocurrency - Bitcoin (an asset that was incredibly successful in 2019-2020) was developed.

Except the opportunity to issue a variety of Steemcoins, the blockchain provides financial institutions with many other opportunities: namely,

- security of payments and funds transfer;

- sending controlled mobile messages;

- tracking of insurance policies issued by various companies to prevent fraud;

- fixation of various financial agreements;

- simultaneous messages of the same content without the possibility of making changes by one party (the same applies to any financial contracts);

- formation of a vicious circle in the field of reinsurance and co-insurance;

- automatic processing of claims in insurance under previously tokenized policies; 
- checking specialists for their qualifications in the field of financial business (banking, insurance, brokerage); and

- fixation of financial guarantees.

Digitalization of internal business processes has opened new opportunities for banks, insurance companies and other financial institutions to develop personalized financial services and differentiate pricing. Customers' identification together with an array of data about them allows you to develop personalized financial services without significant additional operating costs. This area perhaps has the greatest potential for increasing the availability of financial services at a price and rise in the number of financial institutions clients.

The state is represented in all financial processes of society. Influence on money circulation and money supply is provided through the institutions of central banks, tax collection is performed by fiscal services, regulation and control of the financial sector is through regulators. Of course, the state cannot and has no right to stand aside from technological processes in the financial sphere.

Financial activities are subject to state supervision and control. Economic regulations of regulators are becoming stricter due to the growing volume and complexity of financial transactions and require the provision of increasing amounts of information with its complex structuring. Models based on risk assessment of financial institutions (for instance, Basel III in banking and Solvency 2 in insurance) cannot be used without appropriate information technology, processing power and software.

The large-scale participation of the state in financial circulation based on digital technologies has given rise to such terms as RegTech and SupTech.

RegTech is a new domain within the financial industry that applies technology to improve regulatory processes, especially with regards to KYC (Know Your Customer) and AML ( Anti - Money Laundering) [3].

Fuzzy terminology is a fairly common phenomenon in today's digital economy. Thus, the NBU talks about decisions in the field of SupTech (supervisory technologies) and RegTech (regulatory technologies). SupTech can be defined as a set of technologies used by supervisors and market regulators to perform their functions and administrative tasks. Thus, SupTech provides a system of reporting to banks on transactions subject to financial monitoring. RegTech is a set of technologies that optimize the bank's compliance. It means control system over compliance with regulatory requirements [4].

Therefore, the front office digital technologies, first of all, are improvement of marketing activity, and back office - operational, investment and financial. The combined characteristic is the transparency of all financial institution business processes formed on a single technological platform. Each transaction leaves an «electronic footprint», each transaction is permanently tied to the center of financial responsibility and to a specific executor, and each decision can be subsequently subjected to objective analysis. Transparency of business processes builds trust in information for management decisions.

In the coming years, technologies related to the use of artificial intelligence will be introduced in the financial sector, as well as in other economy and business areas. Kai-fu Lee identifies four waves of artificial intelligence: artificial intelligence of the Internet, artificial intelligence for business, artificial intelligence of perception and autonomous artificial intelligence [5]. At the same time, in the author's opinion, the first two waves are already being realized, gradually changing the financial and digital world.

Credit analysis and monitoring using neural networks, extensive use of chatbots based on machine learning technologies, and analyzes the market and consumers with further forecasting (including forecasting of consumer preferences, their behavior in the market) have already been in use financial sector. But many factors constrain the development of artificial intelligence technology in finance and, first of all, this concerns the misunderstanding by many consumers of the technology itself, its complexity (many authors also add the possible uncontrollability factor of AI systems).

Digital technologies have radically changed and continue to change the financial sphere in a short time, a fundamentally new ecosystem of financial business has been formed, consumers of financial services have gained many advantages, and customers have become more thanks to technology.

But there is a lot of research on the threats that are emerging in the new digital society. Many of them are in plain view and this applies primarily to cybersecurity. The issue of cybersecurity is extremely important, because hacker attacks can instantly destroy both critical infrastructure and the financial systems of entire countries. At the same time, taking into account the globalization, the issue of protection should be built at the supranational level. The financial systems of different countries are interconnected. At the same time, many countries have limited opportunities to finance the necessary cybersecurity measures.

At the household level, there is a speed of change in financial services, their diversity, often incomprehensible to many users or technical limitations are threats. Gradually, a layer of people-leaders in the use of digital financial services is formed, and peopleoutsiders who are unable to master new financial services due to lack of education or understanding, due to lack of technical means (smartphones that support financial services). But in the meantime, financial institutions strive for the maximum possible digitalization of financial services because it significantly reduces operating costs. In the near future, there will be situations when a certain circle of people in a specific location will be cut off from the opportunity to receive financial services.

The scaling of financial services, the emergence of new types and kinds of financial assets (including virtual assets) will increase the number of frauds in the financial market. In addition to outright fraud, there are activities of financial institutions within the law, which are based 
on low financial literacy of the population and deliberate information misrepresentation.

The most typical example of this phenomenon is the issuance of fast loans through mobile applications (at 2$2.5 \%$ per annum for each day of credit). This problem could best be solved by proper financial and digital literacy of society and control over the financial market by the state.

The digital technologies impact on the labor market is a more complex challenge. While it had previously been assumed that automation and robotization of processes could affect the segment of unskilled jobs, now this threat has fully spread to the segment of middle and highly qualified workers, the so-called White collar workers.
It is already possible to identify a number of specialties in the financial sector, which may soon be unclaimed in the market. Such professions include insurance agents, emergency commissioners, bank clerks, call center employees, financial lawyers, and tax inspectors. Mentioned and many other professions can be fully automated using algorithms. Moreover, this list will include IT services employees of financial institutions with a certain time lag. Internal business processes on IT issues will be outsourced en masse (this is already being done now), and the algorithms themselves will create the necessary software for doing business (medium term). The rapid spread of digital technologies in the Ukrainian banking sector is accompanying by a decrease in the number of banking institutions branches (Fig.1).

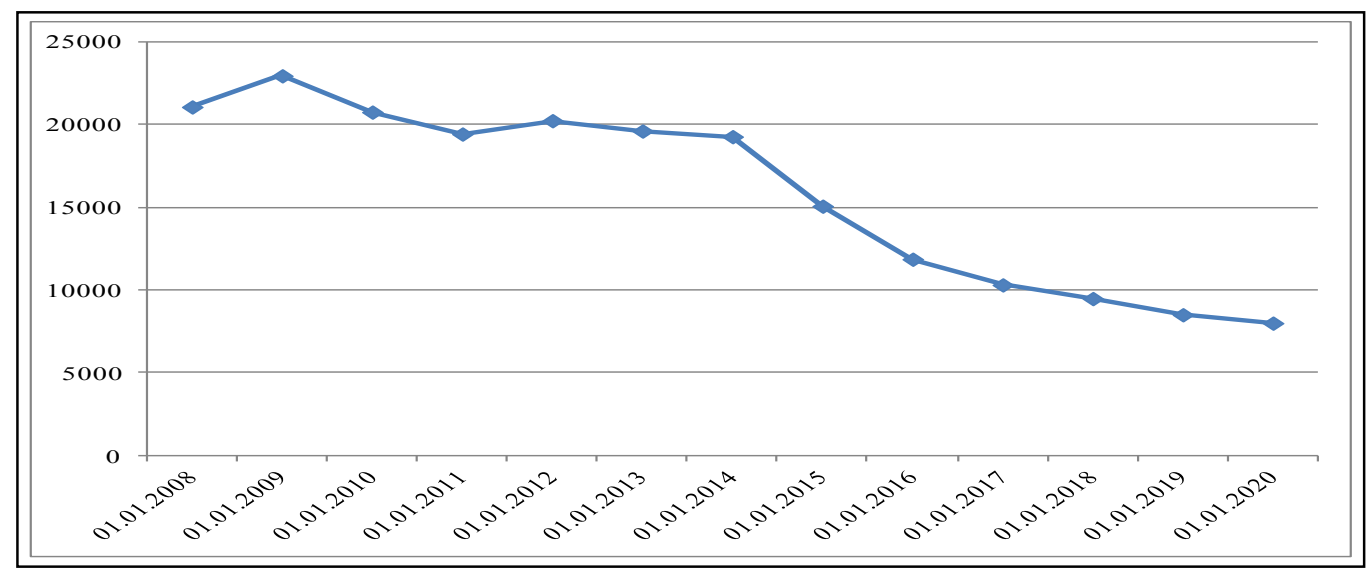

Fig. 1. Dynamics of banking institutions branches in Ukraine in 2008-2020, units Source: generalized basing on [6]

The global financial crisis affected the market infrastructure that had already formed at that time. In particular, the number of branches in 2008-2010 decreased by $7.8 \%$. The main reason was not the closure of banking institutions (their number rose from 175 to 182 during this period), but the development of banking technologies. The crisis has provided an impetus for the cost optimization search, and innovations and new technologies are the only pathway to do that.

The Ukrainian banking services market had been underwent the largest structural changes during the local financial crisis of 2014-2016, when 84 banks left the market [7]. The branches number was reduced by $53.5 \%$. After the market stabilization in 2017, the figure of offices had continued to drop (until 01.10 .2020 by $29 \%$ ) and this reduction has already had a purely technological basis. In 2020, despite the Covid-19 pandemic, the banking system operated profitably, but the accelerating of the adoption process of remote access technologies led to the further closure of branches - their number decreased by $9 \%$ over the year.

The objectivity of the bank branches reduction was described by Chris Skinner in 2014. Historically, retail banks had an extensive branch network. In the 70's, they introduced Automated Teller Machines, in the 80's - call centres, in the 90's - the Internet, and now, in the 2000s, they are introducing mobile technologies [8]. And each of these stages has contributed to a decrease in the number of departments and staff, but there has been a significant acceleration of these processes in recent years.

The banking market of Ukraine was hit the hardest during the crisis of 2014-2016 (Fig. 2). Recovery began after 2017, when provisions for doubtful loans (NPLs) had finally formed. At the same time, there has been an increase in the share of commission income in the total income of the banking system over the past 2 years, which is always a sign of the crisis. In general, in the Ukrainian financial market, banks now do not feel competition from fintech companies, neither in the field of payments nor in the money transfers areas. The mobile Internet banking system is fully controlled by traditional banks.

Privat24 is the most popular Internet mobile banking system in Ukraine. It was created by Privatbank in 2001, but in fact this system became widespread after 2010 . Then a version of the Privat 24 mobile application was launched for download on smartphones that support iOS and Android operating systems. Innovations have made Ukrainian Privatbank one of the most innovative banks in the world. For instance, the bank was one of the first in the world to use one-time SMS passwords more than 10 years ago. 


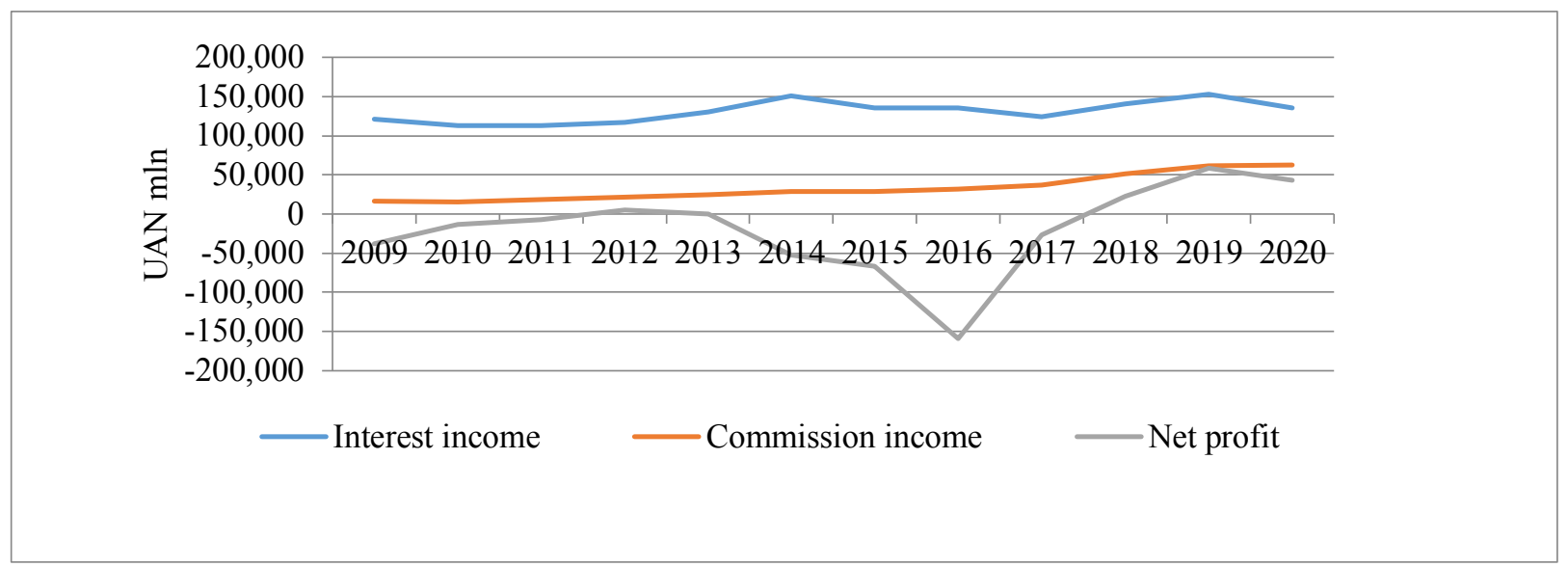

Fig. 2. Interest, commission income and net profit of Ukrainian commercial banks in 2009-2020, UAN mln Source: generalized basing on [6]

The latest innovations, which have gained worldwide recognition, include products such as a payment miniterminal, access to the Internet bank via QR code, online collection, as well as dozens of different mobile applications [9]. The well-known researcher of digital banking Chris Skinner also noted the innovativeness of the Ukrainian Privatbank in his work. The author noted the introduction of an open API architecture and the formation on this basis of a component-oriented banking system and the introduction of the Sender system, which allows companies to communicate with customers and share values via chat without the cost of developing applications. The Sender app received the Best of Show award from the Finovate Fall conference, which took place in New York in the fall of 2014 [10].

Talking about technologies in the banking sector of Ukraine, we cannot but mention another successful example - the Monobank project of the Ukrainian JSC «Universal Bank».

Monobank is a retail product of JSC «Universal Bank», which emerged in cooperation with the Fintech Band. Credit cards are issued for customers, it is possible to place deposits and receive other services within the Monobank. This mobile application makes financial management as convenient as possible. Monobank only works on mobile devices [11]. The Monobank project was created in 2017 by a team of specialists who once worked on the Privat24 system. The work is carried out by the Universal Bank license, which is part of the TAS group. The project was very successful and won the nomination «Best Ukrainian FinTech-startup» in the year of creation, PaySpace Magazine Awards, and in 2018 won the main award in the category «Neobank of the Year» FinAwards 2018. Now Monobank is used more than 3 million customers.

Testing was conducted to assess the public's perception of the business organization form. Testing is an experimental method of diagnosis which are often used in socio-economic research. Tests are classified on various grounds. Thus, according to the types of properties, tests are divided into tests of achievement and personality [12]. Simple personality tests to determine the priorities of using mobile banking were used in the research. Testing was conducted by the authors using Google form among State University of Economics and Technology students and teachers aged 16 to 65 years (over 650 respondents). The question was formulated as follows: What financial service do you personally use? The following possible responses were suggested:

- Privat24;

- monobank;

- other financial institutions;

- I do not use financial services.

The study results are presented in the Table 1.

Table 1. Results of mobile banking users' survey

\begin{tabular}{|l|c|c|c|}
\hline $\begin{array}{c}\text { Age of respondents / Financial } \\
\text { institution (system) }\end{array}$ & $\begin{array}{c}\text { From 16 to 25 } \\
\text { years,\% }\end{array}$ & $\begin{array}{c}\text { From 26 to 45 } \\
\text { years,\% }\end{array}$ & $\begin{array}{c}\text { From 45 to 66 } \\
\text { years,\% }\end{array}$ \\
\hline Privat24 & $319(68,6)$ & $138(97,9)$ & $30(68,2)$ \\
\hline Monobank & $138(29,7)$ & $33(23,4)$ & $6(13,6)$ \\
\hline Other financial institutions & $6(1,3)$ & $2(1,4)$ & - \\
\hline I do not use financial services & $2(0,4)$ & $3(2,1)$ & $8(18,2)$ \\
\hline Total & 465 & 141 & 44 \\
\hline
\end{tabular}

Source: Formed basing on the results of survey among teachers and students of the State University of Economics and Technology and University Colleges

In general, the survey corresponds to the client profile formed by Dmitry Dubilet (the original author and one of the Fintech Band founders). According to his observation, the bank's main clients belong to the age group of 20-40 years, often self-employed persons, those who choose the bank independently (monobank is not engaged in corporate lending, maintenance of pension accounts or salary projects of large enterprises). The 
monobank pricing model is extremely simple Privatbank's tariffs are reduced by $10-30 \%$. This avoids or reduces the number of offices, the utilities' cost, a large number of staff [13]. The research results also indicated that the vast majority of respondents represent Monobank not as a structure of JSC «Universal Bank», but as an independent digital bank.

There are fintech companies that provide transfer and payment services in Ukraine, but their activity are small. Monobank is more popular among young people, and Privatbank is a national leader. Few people do not use financial services at all (do not use either the elderly or for religious reasons). The situation in the banking market under the influence of technology causes two trends - banking productivity increasing and rise of return on invested capital while reducing the number of employees in the industry. Of course, this will also apply to other financial institutions. In general, this confirms the conclusion of a study conducted by Thomas Picketti that, except for a relatively short time in the twentieth century, the rate of return on investment exceeds the level of return on labor [14]. This conclusion is made in more detail, but through the prism of artificial intelligence, and in the study of Kai-Fu Lee [5].

R.Buht and R.Hicks in their research give other views, which relate, on the contrary, job growth in most areas of activity through the introduction of digital technologies [15].

In our opinion, the number of people employed in the financial sector will decline due to the introduction of digital technologies, but this is more a short-term or medium-term trend. Neither banks, nor insurance companies, nor most other financial institutions will be able to completely get rid of branches, even in the long run.

The number of branches and employees will reach a certain minimum level and stabilize. In addition, a new demand for financial services is expected to appearance, and more affluent customers will be served by people. The trend when wealthy citizens prefer to do without digital services, described by Nellie Bowles in a wellknown article Human Contact Is Now a Luxury Good. The author emphasizes that in almost every type of socio-economic activity (medicine, education, business services etc.) there is a people layer who want to communicate with human professionals, rather than with their digital substitutes. The availability of digital technologies and their relatively low cost (the cost reducing process of both equipment and services is likely to be continued for a long time). Undoubtedly, the use of digital technologies no longer stresses a person status [16].

Banks and other financial companies will be sure to leave branches and individual employees for VIP services. Those who have not adapted to the new realities will also need physical care. Supervisors may establish a list of services that financial institutions will provide both online and offline to resolve potential conflicts.

Competition in the financial sector will intensify and digital technologies will play an important role in this. The adoption of the EU Directive on payment services in the domestic market (Payment Services Directive 2015/2366) introduced the concept of «open banking» [17]. The main content of this is the admission to the payment services market of non-banking financial companies, including fintech companies. «Open banking» is based on the possibility of third-party access (their list is determined by law) to the bank customers' accounts and clients' data through the API (Application Programming Interface). Such access can be used both for the implementation of payment services (they are still focused on) and for the development of new financial services by non-banking financial institutions (the same fintech companies). Banks essentially create their own competitors by providing such access.

But consumers of financial services will receive many benefits, including the improve security of payments and money transfers, the reduction of commissions, which will affect all participants in the financial system, the receipt of new financial services.

The PSD2 directive was adopted in 2015, but provided for a two-year implementation period and stepby-step entry into force and came into force only in September 2019. In Europe, banks are actively developing and implementing the Open API to not only meet PSD2 requirements, but to make money. The most popular is the launch of the freemium API (free access to accounts within the requirements of PSD2 with paid access to information and services not covered by PSD2). Most of payment institutions failed to implement enhanced customer authentication (SCA) requirements in a timely manner. This prompted the European Banking Authority (EBA) to recommend postponing the implementation of the SCA until 31 December 2020 [18].

According to the National Bank of Ukraine plans, the implementation of PSD2 in Ukraine is scheduled for completion in 2022 [19]. Today, implementation is impossible due to outdated legislation.

Technology is evolving so rapidly, and its application in business processes is becoming so profound that the financial processes forecasting becomes very vague (the idea of not being able to make objective forecasts at all deserves the attention). It seems that there is a huge field for speculation of a new type due to a combination of rather complex financial instruments (for instance, atypical derivatives with a complex structure) and digital technologies, which are currently understood only by narrow specialists (blockchain, artificial intelligence, machine learning). At the same time, the speculative component of financial markets, which is enormity today, will grow, while the real (issue of securities for project financing) will decrease. At present day, the most significant is the dynamics of the first cryptocurrency bitcoin (Fig.3). 


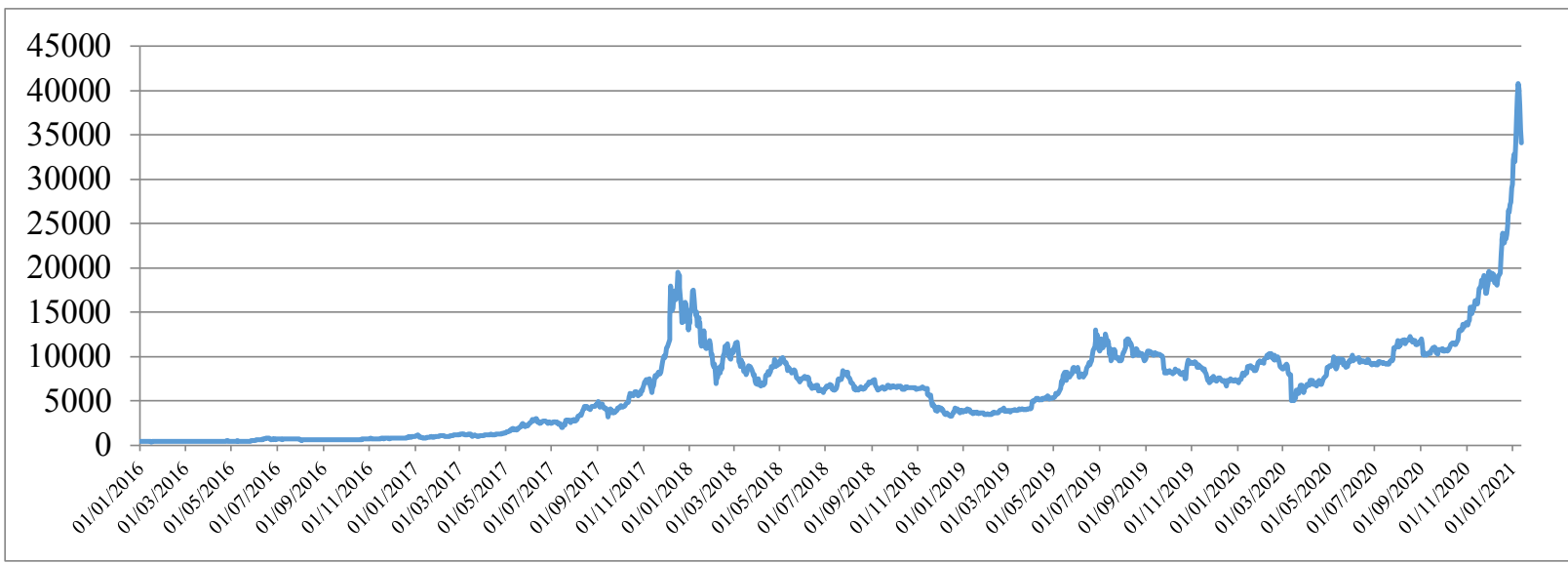

Fig. 3. Dynamics of the bitcoin exchange rate versus the US dollar in 2016-2021

Source: generalized basing on [20]

The standard deviation of the series is 5283 , and the coefficient of variation of $83.56 \%$ indicates an extremely high level of risk associated with the asset.

Cryptocurrency apologists and «crypto-optimists» insist that bitcoin is money (although not controlled by the state). From our point of view, a currency with such fluctuations and complexity of application cannot perform the basic functions of money such as a measure of value and a means of payment. But it probably performs the function of accumulation. It is more correct to consider bitcoin and similar assets as virtual (digital) goods. This is exactly the view presented in the first reading of the Law of Ukraine 923-IX of September 29, 2020 «On Virtual Assets» adopted on December 2, 2020. The Ministry of Digital Transformation of Ukraine, not even the National Bank of Ukraine, has been designated as the regulator of the virtual assets market [21]. The growth of the market for virtual assets, including virtual financial assets, cryptocurrencies and other quasi-money (monetary surrogates) can be predicted with a high probability. The risk is offset by extremely high potential returns and there will always be investors who will invest in virtual assets. The situation with bitcoin is an indicator of investor interest in virtual assets.

Against the background of the COVID-19 coronavirus pandemic, there have been trends of increasing money issuance by central banks, declining interest rates and a collapse in many commodity markets, in the tourism and hotel business, and in passenger traffic. There is more «extra» money in the world, which explains the surge in interest in bitcoin.

The state should limit speculation in the market, but the main efforts need be aimed at protecting the interests of pension funds depositors, life insurance companies, time and current deposits. Investing in speculative assets ought to be prohibited for institutions licensed for such activities.

Failures of information systems related to the human factor, especially in the field of public administration, are a very important danger. The salaries of IT professionals in the public sector are much lower than in the private sector. In Ukraine, this difference is extremely high. This creates a low quality of information logistics, software and personal data protection. The authors observed the investigation of a case where two different people had one pension account (one of these people is a pensioner and the other one is of nonretirement age). The investigation was conducted by three services (Pension Fund, Fiscal Service and Employment Service) and did not reveal anything. The result was obtained by the authors themselves by simple physical verification of documents and facts. The series of passports were different (AK and AM, which is very similar in Ukrainian paper passports), and one person refused to be assigned a taxpayer identification code for religious reasons. Such situations occur periodically in the public sector and most of them are due to low qualifications of performers or low quality software.

The variety of risks posed by digital technology in the financial sector is striking in both quantity and possible consequences. The finances digitalization process is ongoing, which means that both the number of opportunities and the amount of risks will increase.

The state and representatives of the financial business should form a partnership that will aim to form a stable global system based on the following principles:

1. Accessibility - financial services should be available to absolutely all inhabitants of the planet with the help of today's information and communication technologies.

2. Fairness - discrimination in access to certain financial services depending on a person's social status is inadmissible. This will be achieved primarily through the pricing policy of financial institutions.

3. Competitiveness - digital platforms ought to be available to all participants as well as the software necessary for conducting monetary transactions.

4. Monopolization of any financial services at the national and global level is not allowed (except for the issuance of money in the short and medium term).

5. Protection of personal data - financial institutions must reach the consent of the individual to use his data when conducting financial transactions or transferring data to other financial institutions.

6. Control and regulation - only state control and regulation can keep the global financial system from complete chaos and thus protect the interests of individuals and legal entities. 


\section{Conclusion}

Digital technologies are shaping a new financial ecosystem. There have been increasing in the efficiency and productivity of financial institutions both at the level of the front office and at the level of the back office the last 3-5 years. Customers have received many benefits and conveniences, and internal business processes have become much more optimal. But there are amount of new risks and threats which do not attract as much attention as the benefits of new digital technologies. The increase in financial services consumers through mobile and Internet technologies contributes to the growth of financial institutions income, but is the reason for the reduction of jobs in the industry. The article this is illustrated by the banking system of Ukraine example income from commission activities and interest income grew against the background of the continuing decline in the number of banking institutions and employees in recent years.

Very serious challenges for the new financial system related to ensuring a high level of cybersecurity. The banking system demonopolization in the area of payments and remittances, provided for in the EU Directive PSD2, will raise the level of competition in the financial sector, but will lead to the emergence of a large number of new small market participants. At the same time in Ukraine in the field of funds and payments transfer is dominated by commercial banks with their payment services (Privat24, Monobank). The situation will not change, at least in the medium term. But the opening of the payment services market for non-bank financial institutions (in particular, fintech companies) may stimulate the emergence of a new type of fraud.

Use of blockchain technologies, data science, machine learning and especially artificial intelligence, show their effectiveness in many processes and operations. But according to analysis result, these technologies need further thorough research before they are ready to enter the market in full. The volume of financial speculation and outright fraud is growing (this is clearly represented by the dynamics of the bitcoin exchange rate versus the US dollar) with the development of virtual assets. The idea of the uncontrolled money functioning in the case of its implementation can plunge the world into financial chaos.

The link of state control and management in the financial sphere is problematic, because the vast majority of regulatory processes have already been digitized (which led to the emergence of such terms as SupTech and RegTech). At the same time, information technology specialists in the public sector earn much less than in the private sector. This is already affects the government regulation quality in the financial sector.

The solution to the problems of digital finance future lies only in the field of effective public-private cooperation, which should be based on the principles of financial services total accessibility, their fairness, fair competition in financial business, ensuring maximum protection of personal data and improving public supervision and control over the financial institutions.

\section{References}

1. The age of digital interdependence. Report of the UN Secretary Generals High-Level Panel on Digital Cooperation (2020).

https:/www.un.org/en/pdfs/DigitalCooperationreport-for\%20web.pdf

2. Iansiti M. Lakhani K. The Truth about Blockchain. Harvard Business Review. (2017). https://hbr.org/2017/01/the-truth-about-blockchain

3. Patrick Schueffel. The Concise Fintech Compendium (School of Management Fribourg, 2017).

https://www.researchgate.net/publication/32281931 0 The_Concise_Fintech_Compendium

4. Kurcev V. SupTech, RegTech and FinTech - What is it and what is the difference (2019) https://ain.ua/2019/05/17/suptech-regtech-ta-fintech/

5. Kai-Fu Lee. AI Superpowers: China, Silicon Valley, and the New World Order (translated by Punjko V.). Kyiv: Fors Ukraine, 2020, 304 p.

6. Data from supervisory statistics. Website of the National Bank of Ukraine.

https://bank.gov.ua/ua/statistic/supervisionstatist/data-supervision\#5

7. Number of banks in Ukraine. Website of the Ministry of Finance of Ukraine. https://index.minfin.com.ua/ua/banks/stat/count/

8. Skinner C. Digital Bank: Strategies to Launch or Become a Digital Bank (translated by Smirnov S.). Moscow: Ivanov and Ferber, 2015, 320 p.

9. Information about the Bank. Website of PrivatBank. https://en.privatbank.ua/about

10. Skinner C. How fintech firms are using bitcoin blockchain and mobile technologies to create the Internet of value (translated by Jacjuk N.). Moscow: Moscow: Ivanov and Ferber, 2018, 416 p.

11. About Monobank. Universal Bank. https://www.monobank.ua/about?lang=uk

12. Azaryan A, Azaryan R. Fundamentals of scientific research: Kryvyi Rih: KTU Publishing Center, 2010, $230 \mathrm{p}$.

13. Vorona T., Dubilet. D. Business on common sense. 50 ideas how to achieve yours. Kyiv: Force Ukraine, 2020. $256 \mathrm{p}$.

14. Piketty T. Capital in the Twenty-First Century. Moscow: Ad Marginem, 2015, 592 p.

15. Bukht R, Heeks R. Defining. Conceptualising and Measuring the Digital Economy, 13, 2, 143-172 (2018). DOI: 10.17323/1996-7845-2018-02-07

16. Bowles N. Human Contact Is Now a Luxury Good (New York, USA, 2019)

17. Payment Services Directive 2015/2366. https://ec.europa.eu/info/law/payment-services-psd2-directive-eu-2015-2366_en

18. Shulyar R., Burlaka B. Fintech VS Banking. What Will Change the New Payment Standard of the European Union? (2020). https://marchenkopartners.com/fintehom-pobankingu-shho-zminit-novij-platizhnij-standartyevropejskogo-soyuzu/) 
19. Payment infrastructure of Ukraine goes over to the international standard ISO 20022.

https://bank.gov.ua/ua/news/all/platijna-infrastrukturaukrayini-perehoditime-na-mijnarodniy -standart-iso20022

20. Bitcoin USD (BTC-USD) Stock Historical Prices \& Data. https://finance.yahoo.com/quote/BTCUSD/history/

21. Draft Law of Ukraine «On Virtual Assets» from 11.06.2020 №3637 